\title{
Economic Instruments for Lake Water Quality Management in Japan
}

\author{
Thomas Ballatore ${ }^{*}$, Masahisa Nakamura ${ }^{* *}$, and Tomonori Matsuo ${ }^{*}$ \\ *University of Tokyo, Department of Urban Engineering, 7-3-1 Hongo, Bunkyo-ku, Tokyo 113, Japan \\ **Lake Biwa Research Institute, 1-10 Uchidehama, Otsu-shi, Shiga-ken 520, Japan
}

\begin{abstract}
This paper analyzes the introduction of transferable discharge permits for industrial phosphorus effluent control in Japan through a case study of Lake Biwa. We review the laws and the regulation system that is built on uniform, technology-based standards and show that such standards can be economically inefficient because they ignore differences in marginal abatement costs for individual polluters. It is found that there are significant variations in marginal abatement cost for industrial phosphorus removal that are not accounted for under the current type of regulation. A transferable discharge permit system that accounts for such differences is proposed and implementation problems are discussed.
\end{abstract}

KEYWORDS: Transferable discharge permits, Lake Biwa, phosphorus, eutrophication, lake management

\section{Introduction}

Despite its success since the early 1970's in combating pollution due to environmental health items through laws and regulations, Japan has made little progress with respect to living environment items such as COD, nitrogen, and phosphorus for lakes and enclosed water bodies, and through time, phenomena such as eutrophication have become a growing concern. For example, fewer lakes and marshes were in compliance with ambient COD standards in 1995 than in 1974. The situation shows few signs of improving without further regulatory action, yet most industrial sources discharging into lakes have already implemented the standard pollution control technologies and face high and rising costs under stricter control. Therefore, if any tighter industrial regulations are implemented, they should be efficient so that they will lead to the largest improvements in water quality at the lowest cost. Against this backdrop, we analyze the case of Lake Biwa, examine the current regulatory system, and propose a new approach that can incorporate economic efficiency concerns. The focus is on phosphorus because of its critical role as limiting nutrient in eutrophication.

\section{Critique of Current Regulations}

\section{Overview of Relevant Laws and Regulations}

An outline of the relevant laws and regulations is presented as Figure 1 on top of next page. The Basic Environmental Law sets Environmental Quality Standards (EQS) for phosphorus in lakes. Lake Biwa is designated as a Category II lake and the EQS phosphorus standard is $10 \mu \mathrm{g} / \mathrm{l}$ (Environmental Agency, 6, 8). As of 1995, Lake Biwa's northern basin was in compliance $(8 \mu \mathrm{g} / \mathrm{l})$, but the southern basin was not $(20 \mu \mathrm{g} / \mathrm{l})$ (Shiga Prefectural Government 1997b, 6). Note that such ambient standards serve as goals and are not legally binding, as are effluent standards.

The Water Pollution Control Law does two main things that are relevant for this discussion. First, it sets national, concentration-based phosphorus effluent standards for specified facilities designated by Cabinet order. The level is a daily average of $16 \mathrm{mg} / \mathrm{l}$. Second, it authorizes prefectural governors to set stricter concentration-based standards when it is determined that the $16 \mathrm{mg} / \mathrm{l}$ standard will be insufficient to meet the ambient standard (Environmental Agency, 12). 


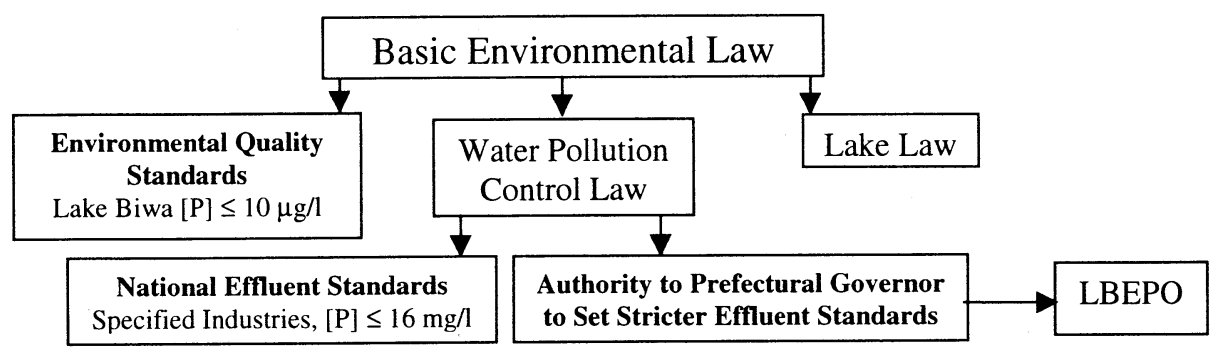

Figure 1. Outline of Relevant Laws and Regulations

Under this authority, Shiga passed the Lake Biwa Eutrophication Prevention Ordinance (LBEPO) in 1979 mandating stringent industrial effluent standards for industries with flow rates over $30 \mathrm{~m}^{3} /$ day. The ordinance was updated in 1996 to include smaller companies discharging between 10-30 $\mathrm{m}^{3} / \mathrm{day}$ (Shiga Prefectural Government 1997b, 13). After years of strong control relative to other sources, industrial sources accounted for $27.2 \%$ of the phosphorus load to Lake Biwa in 1995 (Ibid.). Data on nonpoint source pollution, although important for the regulator, are not known with certainty. The current industrial effluent standards are shown in Table 1 below.

The Lake Law of 1985 has many interesting provisions, but none that supercede the Shiga Ordinance with respect to industrial phosphorus effluent standards.

Table 1. Effluent Phosphorus Standards for Industries in Shiga Prefecture

\begin{tabular}{|l|l|l|l|}
\hline Type of Industry & Flow Rate, $\mathrm{m}^{3} / \mathrm{day}$ & $\begin{array}{l}{[\mathrm{P}] \text { standard, } \mathrm{mg} / \mathrm{l} \text { for }} \\
\text { Existing Sources }\end{array}$ & $\begin{array}{l}{[\mathrm{P}] \text { standard, } \mathrm{mg} / \mathrm{l} \text { for }} \\
\text { New Sources }\end{array}$ \\
\hline Food & $10-30$ & 8 & 2 \\
& $30-50$ & 4 & 2 \\
& $50-1000$ & 3 & 1.5 \\
& $1000 \sim$ & 1 \\
\hline Lunch Box & $10-30$ & 2 & 6 \\
& $30-50$ & 8 & 4 \\
& $50-1000$ & 5 & 3 \\
& $1000 \sim$ & 5 & 2 \\
\hline Textiles & $10-30$ & 3 & 2 \\
& $30-50$ & 6 & 1.2 \\
& $50-1000$ & 2 & 0.8 \\
\hline Chemicals & $1000 \sim$ & 1.5 & 0.5 \\
& $10-30$ & 1 & 2 \\
& $30-50$ & 5 & 1.2 \\
& $50-1000$ & 2 & 0.8 \\
\hline Gelatin & $1000 \sim$ & 1.5 & 0.5 \\
& $10-30$ & 1 & 2 \\
& $30-50$ & 5 & 1.2 \\
& $50-1000$ & 2 & 0.8 \\
\hline Others & $1000 \sim$ & 1.5 & 0.5 \\
& $10-30$ & 2 & 1 \\
& $30-50$ & 1.5 & 0.6 \\
& $50-1000$ & 1.2 & 0.5 \\
\hline
\end{tabular}

Source: Shiga Prefectural Government 1997a, 97. 
Determination of Current Standards

Oka (1995) has provided an analysis of the development of phosphorus and nitrogen standards under the LBEPO. The standards are essentially uniform and technology-based. For phosphorus, it was assumed that existing factories could achieve an average of $1 \mathrm{mg} / \mathrm{l}$ in process wastewater by using the coagulation-sedimentation process. The difference in standards among industries is due to variations in the percentages of process, cooling and other water, with the exception of food industries, which were assumed to have technical problems in removing phosphorus (Ibid.). The standards for new industries were based on one of the following three assumptions: one, the phosphorus concentration is $1 / 2$ that of existing factories; two, $90 \%$ of phosphorus is removed from process wastewater; or three, phosphorus concentration is $1 / 2$ of the actual process wastewater of existing factories (Ibid.).

Such uniform, technology-based standards serve many goals, yet they have been criticized on the grounds that they are economically inefficient because they ignore variations in marginal abatement cost among sources. In the next section, we present a simple example to show why this omission can be significant.

\section{Economic Efficiency in Environmental Regulation}

Consider a simple example. Assume there are two companies, $\mathrm{A}$ and $\mathrm{B}$, which are each discharging $10 \mathrm{~kg}$ P/day into a lake. Their abatement cost data is estimated in Table 2 . The regulatory agency calculates that the current cumulative phosphorus load of $20 \mathrm{~kg}$ P/day will lead to eutrophication, and decides the total load should be reduced to $10 \mathrm{~kg}$ P/day. The question is how to best accomplish that goal. One way would be to require both companies to cut emissions by half. In that event the total cost would be $89 \times 10^{5}$ yen/day. But consider if $\mathrm{A}$ were to abate to a level of $3 \mathrm{~kg} \mathrm{P} / \mathrm{day}$ and if B were to abate to a level of $7 \mathrm{~kg} \mathrm{P} / \mathrm{day}$, then the total cost would be $57 \times 10^{5}$ yen/day and the cumulative load would still be the desired $10 \mathrm{~kg}$ $\mathrm{P} /$ day. It ends up that the allocation of $3 \mathrm{~kg} \mathrm{P} /$ day to $\mathrm{A}$ and $7 \mathrm{~kg}$ P/day to $\mathrm{B}$ is the least cost solution for achieving the desire standard of $10 \mathrm{~kg}$ P/day, and it is where the marginal abatement costs for both companies are equal. Theoretically, there are various ways of achieving the least cost solution. For example, the regulator could simply assign permits according to the least cost solution, that is 3 permits to $A$ and 7 permits to $B$, where 1 permit

Table 2. An Example of Illustrating the Importance of Equalizing Marginal Costs

\begin{tabular}{|c|c|c|c|c|}
\hline \multirow[t]{2}{*}{$\begin{array}{l}\text { Emissions, } \\
\mathrm{kg} \mathrm{P} / \text { day }\end{array}$} & \multicolumn{2}{|c|}{$\begin{array}{l}\text { Marginal Abatement Costs, } \\
10,000 \text { yen/day }\end{array}$} & \multicolumn{2}{|c|}{$\begin{array}{l}\text { Total Abatement Costs, } \\
10,000 \text { yen/day }\end{array}$} \\
\hline & Company A & Company B & Company A & Company B \\
\hline 10 & 0 & 0 & 0 & 0 \\
\hline 9 & 1 & 3 & 1 & 3 \\
\hline 8 & 2 & 6 & 3 & 9 \\
\hline 7 & 3 & 12 & 6 & 21 \\
\hline 6 & 4 & 20 & 10 & 41 \\
\hline 5 & 6 & 32 & 16 & 73 \\
\hline 4 & 8 & 48 & 24 & 121 \\
\hline 3 & 12 & 69 & 36 & 190 \\
\hline 2 & 20 & 100 & 56 & 290 \\
\hline 1 & 40 & 160 & 96 & 450 \\
\hline 0 & 100 & 250 & 196 & 700 \\
\hline
\end{tabular}


allows a company to discharge $1 \mathrm{~kg}$ P/day. There are several other methods known as economic instruments that could be used to achieve the same result. A tax or subsidy set equal to the marginal cost at the optimum $\left(12 \times 10^{5}\right.$ yen $/ \mathrm{kg}$ P) could theoretically achieve the same least cost distribution. In this paper, we focus on the economic instrument known as transferable discharge permits (TDP). The regulator would initially distribute a total of 10 permits between the two companies and allow them to trade if they desired. We can see that there is an economic incentive to trade until the marginal costs are equalized.

\section{Analysis of Industrial Phosphorus Abatement Costs}

There are three reasons for believing that marginal abatement cost vary between firms. First, if we examine the two major phosphorus removal methods from an engineering point of view, we see that there is a fundamental, scientific basis for expecting marginal abatement cost variation. For example, costs for the coagulation-sedimentation process are affected by influent phosphorus concentration, suspended solids, alkalinity, $\mathrm{pH}$, chemical cost and transportation, reliability of supply, sludge handling facilities, ultimate disposal methods, and process compatibility (Tchobanoglous and Burton, 741), all of which are site-specific. In addition, for biological treatment, especially enhanced biological phosphorus removal, we know that phosphorus removal efficiency depends on many factors including the availability of easily degradable carbon sources and the influent COD/P ratio. Besides these operating costs, there are variations in capital cost, which depend on site-specific factors such as space availability.

Second, the opinions of experts confirm the fact that marginal abatement costs can vary widely. In interviews with the section head of the Environmental Agency's water quality bureau and with a registered engineer at a major pollution control equipment manufacturer, this point has been made clear, although both quantitative data and final regulatory solutions remain elusive.

Third, a survey of companies in Shiga indicates that marginal abatement costs vary not only with industrial type and flow rate, but also with site-specific parameters, such that companies of similar type and flow rate often have significantly different marginal abatement costs (Shiga Prefectural Office 1995). While such apparently random deviations may be caused by inconsistencies in the response methodologies of individual companies, they seem to be in accord with the first two points of this section.

\section{Two Regulatory Approaches: Central Planning versus Market}

Let us consider two regulatory schemes that incorporate economic efficiency concerns under the assumption that Shiga prefecture will tighten industrial phosphorus effluent standards on the currently specified industries. One approach is to develop an enhanced version of the current command-and-control approach by setting standards that take an individual firm's abatement costs into account. Three main tasks for the regulator are as follows: first, decide how much to cut total emissions; second, accurately determine the phosphorus abatement costs for all firms, perhaps through a comprehensive survey along with input from technological experts; finally, set differential standards for each polluter so that when all firms meet their individual standard, all marginal abatement costs will be the same and so that the sum total of all emissions will be equal to the previous total minus the desired decrease.

Because marginal abatement costs are difficult to determine, we consider a second approach: transferable discharge permits. The regulator's two main tasks are as follows: first, as before, decide how much to cut total emissions; and second, assign initial permit 
distributions in any way, relying on trading and negotiation between polluters to determine cost allocations. A simple percentage cutback for all levels listed in Table 1 would be one possible basis for an initial permit distribution, although other initial distributions may better serve to distribute total cost in more politically acceptable ways. In this research, it has become clear that there is a lack of comprehensive, applicable cost data; moreover, it is doubtful that such a data set can be constructed with satisfactory accuracy. In addition, when we consider alternatives to the traditional end-of-pipe pollution controls, the cost data become even more site-specific and beyond the ability of the regulator to accurately estimate. Therefore, we can expect an idealized TDP program to be more efficient at equalizing marginal costs; however, significant obstacles exist between such idealizations and actual implementable programs. In the next section we turn our attention to these problems.

\section{TDP Implementation Issues}

TDPs have been tried before in several cases in the United States, but have often not lived up to expectations because of implementation problems. Before any TDP scheme is introduced, these problems must be examined in the Japanese context.

\section{Permit Definition}

Permits are usually defined in terms of mass loading such as $\mathrm{kg} /$ day. The current regulations for Lake Biwa are concentration-based. A TDP regime would require a shift to load-based regulations (not soryo kisei, but fukaryo kisei) which may be possible under provisions provided in the Lake Law, but for various reasons, has yet to be initiated in Shiga. In addition, the duration of the permit must be defined as well as the trading zones when location effects are of concern.

\section{Monitoring and Enforcement}

It is not clear if a TDP system would lead to higher monitoring and enforcement costs than relative to either the current regime or the enhanced command-and-control model proposed in the previous section. On one hand, a load-based permit may require daily calculations instead of the monthly testing required for maximum concentration-based permits. On the other hand, it is not obvious that the COD load-based permits issued for Tokyo Bay, Ise Bay, or the Inland Sea have led to a significant increase in monitoring and enforcement costs. Furthermore, Japanese companies have an excellent record of complying honestly with regulations and there is no reason to believe that would change.

\section{Statutory Basis}

The question of whether the TDP approach is legal under Japanese Law is not clear. The law does not explicitly allow or prohibit such trading, although the Basic Environmental Law recognizes the need for further study and consideration of economic instruments. As long as the permit purchasing industries kept their effluent concentrations below the $16 \mathrm{mg} / \mathrm{l}$ mandated by the Water Pollution Control Law, the decision to allow trading seems to be up to Shiga Prefecture and its strict LBEPO. Nevertheless, for the system that involves permit trading in conjunction with a tightening of effluent standards, we expect that regulated companies which are in compliance with the LBEPO standards will have little incentive to purchase permits for levels of discharge higher than current levels, because capital investments have already made and they are successfully operating that equipment. 


\section{Industry Behavior in a Permit Market}

Would companies trade permits? The lack of trading in some permit markets has been a significant issue in the United States. Companies base such decisions on a complex calculus, which includes not only economic factors, but also non-economic ones as well. For example, companies may be concerned about their image if they were significant buyers of permits. Also, there may be local pressures, in the form of voluntary pollution control agreements between companies and local citizens that constrain a company's decisions.

\section{Conclusion}

In this paper, we considered the subject of economic efficiency in regulation for lake water quality management in Japan through the case of Lake Biwa. We have shown the importance of equalizing marginal costs and that variations in marginal costs exist and are difficult for a regulatory agency to know well. This implies that there are serious constraints on command-and-control systems that try to account for the variations and that a decentralized market may be better at exploiting such differences. We proposed a basic TDP program and examined some of the issues that are relevant for implementation in the Japanese context, yet many issues remain unresolved and we have not yet come to a conclusion about the applicability of permit trading in this case. Finally, we have not considered the control other sources such as nonpoint sources, yet the application of the efficiency concept looks promising and will be pursued. Interestingly, even though marketbased approaches are not part of the traditional Japanese regulatory framework, they may have a better chance of succeeding in Japan that in traditionally market-oriented cultures like America, because of the systems that are already in place in Japan.

\section{ACKNOWLEDGEMENTS}

The authors would like to thank all those who have contributed to this work, especially Toshiaki Kagatsume, Ryozo Kojima, Hideki Minamikawa, and Eri Nakajima. Any remaining errors are the responsibility of the authors. This work was funded in part by a Monbusho scholarship for the lead author.

\section{REFERENCES}

Environmental Agency, Water Quality Bureau. 1996. Water Environment Management in Japan.

Oka, Toshihiro. 1995. "Command and Control Approach for Water Pollution Control in Japan: the Experience of Lake Biwa Nutrient Control," Paper presented at the 1995 Environmental Economics Workshop for Lake Biwa Eutrophication Control, Lake Biwa Research Institute, Shiga, Japan.

Shiga Prefectural Government, Environmental Policy Division. 1995. Unpublished Survey Data.

1997a. Environmental White Paper.

1997b. Shiga's Environment: Water Quality.

Tchobanoglous, George and Franklin L. Burton, eds. Wastewater Engineering: Treatment, Disposal, and Reuse $3^{\text {rd }}$ Ed. (New York: McGraw Hill, 1991). 